\title{
Genetic Recombination in Streptomyces fradiae by Protoplast Fusion and Cell Regeneration
}

\author{
By RICHARD H. BALTZ \\ Biochemical Development Division, Eli Lilly and Company, Indianapolis, \\ Indiana 46206, U.S.A.
}

(Received 18 October 1977; revised 16 February 1978)

Conditions for highly efficient genetic recombination in Streptomyces by protoplast fusion are described. Protoplasts of $S$. fradiae and $S$. griseofuscus were formed by a modification of the glycine-lysozyme-lytic enzyme method (Okanishi, Suzuki \& Umezawa, 1974). Regeneration of cells from protoplasts was monitored throughout the growth cycle and was most efficient when cells of either $S$. fradiae or $S$. griseofuscus were taken from the transition phase between the exponential and stationary growth phases. Fusion of protoplasts carrying different auxotrophic or chromosomal drug-resistance markers was achieved by treatment with polyethylene glycol, and high frequencies of stable genetic recombinants were obtained.

\section{INTRODUCTION}

Genetic recombination by a system similar to conjugation in the Enterobacteriaceae has been demonstrated with several antibiotic-producing species of Streptomyces (Hopwood, 1967; Friend \& Hopwood, 1971; Coats \& Roeser, 1971; Hopwood et al., 1973; Alačević, Strašek-Vešligaj \& Sermonti, 1973; Akagawa, Okanishi \& Umezawa, 1975; Coats, 1976; Hopwood, 1976). Genetic recombination in $S$. coelicolor is mediated by two fertility plasmids, SCP1 (Hopwood et al., 1973) and SCP2 (Bibb, Freeman \& Hopwood, 1977). SCP1 also codes for synthesis of and resistance to the antibiotic methylenomycin A (Wright \& Hopwood, 1976a), while the $S$. coelicolor chromosome codes for the synthesis of a second antibiotic, actinorhodin (Wright \& Hopwood, 1976b). Genetic mapping and linkage analysis in other Streptomyces species have also revealed plasmid-determined (Akagawa et al., 1975) and chromosome-determined (Coats \& Roeser, 1971; Alačević, 1976) antibiotic activities.

Strain development and genetic analysis of several other economically important Streptomyces species, however, has been hindered by the apparent lack of natural fertility in these strains, and the lack of transduction and transformation systems (Hopwood et al., 1973). A more general means to effect genetic recombination in Streptomyces would therefore be quite useful.

Polyethylene-glycol-induced protoplast (or cell) fusion has recently been demonstrated in several eukaryotic systems (Ferenczy, Kevei \& Szegedi, 1975; Anné \& Peberdy, 1976; Jones et al., 1976; Power et al., 1976; Pontecorvo, Riddle \& Hales, 1977; Sipiczki \& Ferenczy, 1977) and in the prokaryotic genus, Bacillus (Fodor \& Alföldi, 1976; Schaeffer, Cami \& Hotchkiss, 1976). This technique appears to have potential broad utility to effect genetic recombination in prokaryotic micro-organisms, particularly in those lacking classical recombination systems. A key factor in the utility of this technique is the capability of fused bacterial protoplasts to regenerate cell walls and thus viable cells. In this communication, I describe a highly efficient genetic recombination system for Streptomyces using protoplast fusion and efficient cell regeneration. 


\title{
Table 1. Origin of S. fradiae strains used in this investigation
}

$\begin{array}{lc}\text { Strain } & \text { Relevant genotype or phenotype* } \\ \text { C373 } & \text { Spo } \\ \text { M1 } & \text { spo-1 } \\ \text { AR11 } & \text { spo-1 cys D1 } \\ \text { AR17 } & \text { spo-1 metB2 } \\ \text { AR15 } & \text { spo-1 metA5 arg-2 } \\ \text { AR30 } & \text { spo-1 metA5 arg-2 spc-2 }\end{array}$

\author{
Sourcet \\ Soil isolate \\ Spontaneous mutant of $\mathrm{c} 373$ \\ MNNG of $\mathrm{Ml}$ \\ MNNG of $M 1$ \\ MNNG of $M 1$ \\ Spontaneous mutant of AR 15
}

* The spo marker refers to loss of ability to form aerial mycelium and aerial spores. This mutation also renders the strain incapable of producing the antibiotic tylosin during colony growth on nutrient agar plates. The $s p c$ marker refers to resistance to spectinomycin at $50 \mu \mathrm{g} \mathrm{ml}^{-1}$. The auxotrophic marker designations are defined by nutritional requirements and are the same as those of Hopwood et al. (1973).

$\uparrow$ MNNG indicates $N$-methyl- $N^{\prime}$-nitro- $N$-nitrosoguanidine mutagenesis.

\section{METHODS}

Media. TS broth contained $30 \mathrm{~g}$ trypticase soy broth (BBL) per litre distilled water. NC agar contained $8 \mathrm{~g}$ nutrient broth (BBL or Difco) and $15 \mathrm{~g}$ agar per litre distilled water; $\mathrm{Ca}\left(\mathrm{NO}_{3}\right)_{2}$ was sterilized separately and added to 4.0 mM. Modified medium R2 was as described by Okanishi, Suzuki \& Umezawa (1974) except that $1.8 \mathrm{~g} \mathrm{~L}$-asparagine was substituted for proline as the nitrogen source. Medium $\mathrm{P}$ was as described by Okanishi et al. (1974).

Streptomyces strains. Streptomyces fradiae C373 (ATCC 19609) is a filamentous streptomycete used in the commercial production of the macrolide antibiotic tylosin. Derivatives of strain c373 used in this study are listed in Table 1. Streptomyces griseofuscus ATCC 23916, a rapidly growing filamentous streptomycete highly sensitive to certain actinophages (Baltz \& Radue, unpublished), was also used in this study. Auxotrophic mutants were induced by a $N$-methyl- $N^{\prime}$-nitro- $N$-nitrosoguanidine mutagenesis procedure similar to that of Delić, Hopwood \& Friend (1970) except that mycelial fragments rather than spores were used (Seno, Radue \& Baltz, unpublished).

Growth conditions. Both Streptomyces species were grown in TS broth at $34{ }^{\circ} \mathrm{C}$ on a New Brunswick rotary water bath shaker at about $240 \mathrm{rev}$. $\mathrm{min}^{-1}$. Flasks containing TS broth were inoculated with lyophilized or frozen vegetative mycelia or spores and grown until mycelial masses developed (usually 24 to $48 \mathrm{~h}$ ). The mycelia were homogenized by several passages in a Teflon pestle tissue grinder (A. H. Thomas Co., Philadelphia, Pennsylvania, U.S.A.). The homogenization procedure broke the large mycelial masses into small units ranging from several to about 50 cells per colony-forming unit (c.f.u.). Homogenized mycelia were more uniformly fragmented by ultrasonic treatment (see below and Results) and were also more susceptible to rapid uniform protoplasting by lysozyme treatment than were larger unhomogenized mycelia. Homogenized and/or ultrasonically fragmented cells were added to secondary growth flasks (usually at a $1: 10$ to $1: 100$ dilution) and further incubated for 16 to $24 \mathrm{~h}$. This procedure usually facilitated rapid exponential growth with relatively large numbers of growth centres and eliminated development of very large mycelial masses which did not fragment well on ultrasonic treatment. Growth was followed by monitoring the absorbance at $600 \mathrm{~nm}\left(A_{600}\right)$ and the number of colony-forming units after ultrasonic fragmentation of mycelia.

Ultrasonic fragmentation of mycelia. Cells grown in liquid culture were homogenized and diluted twofold in TS broth, and $20 \mathrm{ml}$ was added to a $30 \mathrm{ml}$ polypropylene chemical container (Bel Art). The tip of the ultrasonic probe (Branson sonifier, model W185) was immersed about $1.5 \mathrm{~cm}$ into the broth and mycelia were fractured for 5 to $10 \mathrm{~s}$ at $76 \mathrm{~W}$.

Protoplast formation and cell regeneration. Streptomyces fradiae mycelia fractured ultrasonically were added to TS broth supplemented with $0.4 \%$ (w/v) glycine and grown for at least seven cell doublings. Mycelia were then homogenized or fragmented ultrasonically for $3 \mathrm{~s}$, rather than the normal 5 to $10 \mathrm{~s}$. (Mycelia grown in glycine were fragmented more rapidly by ultrasonic treatment, and longer treatments resulted in substantial loss in viability.) Cells were diluted in the same medium and grown to various absorbances before protoplasting. Mycelia to be protoplasted were washed three times in medium P, homogenized and treated with $1 \mathrm{mg}$ lysozyme $\mathrm{ml}^{-1}$ for $1 \mathrm{~h}$. Usually, conversion of mycelia to stable protoplasts was complete by about $15 \mathrm{~min}$ as judged by phase contrast microscopy. Protoplasts were quantified by direct counts in a haemocytometer and/or by measuring $A_{600}$. Protoplasts were washed two or three times by centrifugation and resuspension in medium $\mathrm{P}$, diluted in medium $\mathrm{P}$ and plated on modified medium $\mathbf{R} 2$ for viable counts to determine cell regeneration. Colony formation from non-protoplasted cells was determined 
by (i) diluting protoplasts in distilled water and plating on medium $\mathbf{R} 2$ or (ii) diluting in medium $\mathbf{P}$ and plating on NC agar medium.

Protoplasts of $S$. griseofuscus were prepared in the same way except that cells were grown in TS broth plus $0.8 \%(\mathrm{w} / \mathrm{v})$ glycine.

Protoplast fusion and genetic recombination. Protoplasts $\left(0.5 \mathrm{ml}\right.$; about $2 \times 10^{8}$ to $\left.4 \times 10^{8} \mathrm{ml}^{-1}\right)$ from each of two strains were mixed and centrifuged in a clinical centrifuge. The pellet was resuspended in $0 \cdot 1 \mathrm{ml} \mathrm{medium} P$ and mixed with $0.9 \mathrm{ml} 40 \%(\mathrm{w} / \mathrm{v})$ polyethylene glycol 6000 (PEG) in medium P (prepared by filter sterilization). The PEG-treated protoplasts were diluted after $30 \mathrm{~s}$ at $23{ }^{\circ} \mathrm{C}$ and plated on medium R2. Prototrophic colonies were picked and streaked on R2 and NC agar. All colonies tested contained prototrophic recombinants which were stable upon recloning, but many also contained a minority of auxotrophic parental types. Stable prototrophic recombinants were streaked on NC agar plates containing $50 \mu \mathrm{g}$ spectinomycin $\mathrm{ml}^{-1}$ to determine resistance to the antibiotic.

\section{RESULTS}

\section{Formation of protoplasts}

Streptomyces fradiae and S. griseofuscus became sensitive to lysozyme after growth in the presence of a partially growth-inhibitory concentration of glycine. Figure $1(a)$ shows the growth kinetics of $S$. fradiae in TS broth with and without $0.4 \%$ glycine. The presence of $0.4 \%$ glycine increased the cell doubling time from about $1.6 \mathrm{~h}$ to $2.7 \mathrm{~h}$. Essentially complete growth inhibition was achieved at $0.6 \%$ glycine (not shown). Cells grown for about seven cell doublings or more in the presence of $0.4 \%$ glycine were highly sensitive to lysozyme and formed stable protoplasts in medium $P$. The number of cells surviving this treatment was typically about 1 in $10^{6}$ to $10^{4}$. There was a lengthy (about $20 \mathrm{~h}$ ) transition phase between the classical exponential and stationary growth phases during which the $A_{600}$ increased from about 2.0 to $9 \cdot 0$ (Fig. $1 a$ ); the relevance of this growth phase to cell regeneration is discussed below.

Addition of $0.8 \%$ glycine to TS broth increased the cell doubling time of S. griseofuscus from about $1 \mathrm{~h}$ to $2 \mathrm{~h}$ (Fig. $1 \mathrm{~b}$ ). With this concentration of glycine, S. griseofuscus cells grown for about seven cell doublings were quite susceptible to protoplasting by lysozyme treatment. The number of cells surviving lysozyme treatment was also about 1 in $10^{6}$ to $10^{4}$. Cells of $S$. fradiae and $S$. griseofuscus grown in the absence of glycine or grown for only three to four cell doublings in glycine formed protoplasts very poorly $(<90 \%$ conversion in $16 \mathrm{~h}$ with $1 \mathrm{mg}$ lysozyme $\mathrm{ml}^{-1}$ ). Growth of $S$. griseofuscus proceeded from the exponential to the stationary phase quite rapidly with very little increase in cell mass during the transition (Fig. $1 b$ ).

\section{Regeneration of cells from protoplasts}

The efficiency of cell regeneration from protoplasts of $S$. fradiae and $S$. griseofuscus varied during the growth cycle and was highest if protoplasts were prepared from cells in the transition phase between the exponential and stationary growth phases (Fig. $1 a, b$ ). About $10^{8}$ colony-forming protoplasts were obtained per $A_{600}$ unit of $S$. fradiae or $S$. griseofuscus mycelia during this period. Streptomyces fradiae protoplasts prepared from cells grown to an $A_{600}$ of about $0 \cdot 4$ also regenerated rather efficiently. However, cells from later stages of exponential growth regenerated poorly This pattern was reproduced in other experiments, except that protoplasts from the mid- to late-exponential growth phase were regenerated even more poorly than shown in Fig. 1(a). Stationary phase protoplasts of $S$. fradiae and $S$. griseofuscus also regenerated very poorly.

The process of cell regeneration from $S$. fradiae protoplasts was generally slow and asynchronous. The first visible colonies from regenerated protoplasts appeared after 3 to $4 \mathrm{~d}$ incubation, while the last appeared after 7 to $12 \mathrm{~d}$, depending on the growth phase of the cells before formation of protoplasts. The time required for one-half of the regenerating protoplasts to appear as visible colonies varied from 3 to $7 \mathrm{~d}$ and depended on the growth phase of the cells before formation of protoplasts. In contrast, when ultrasonically prepared 


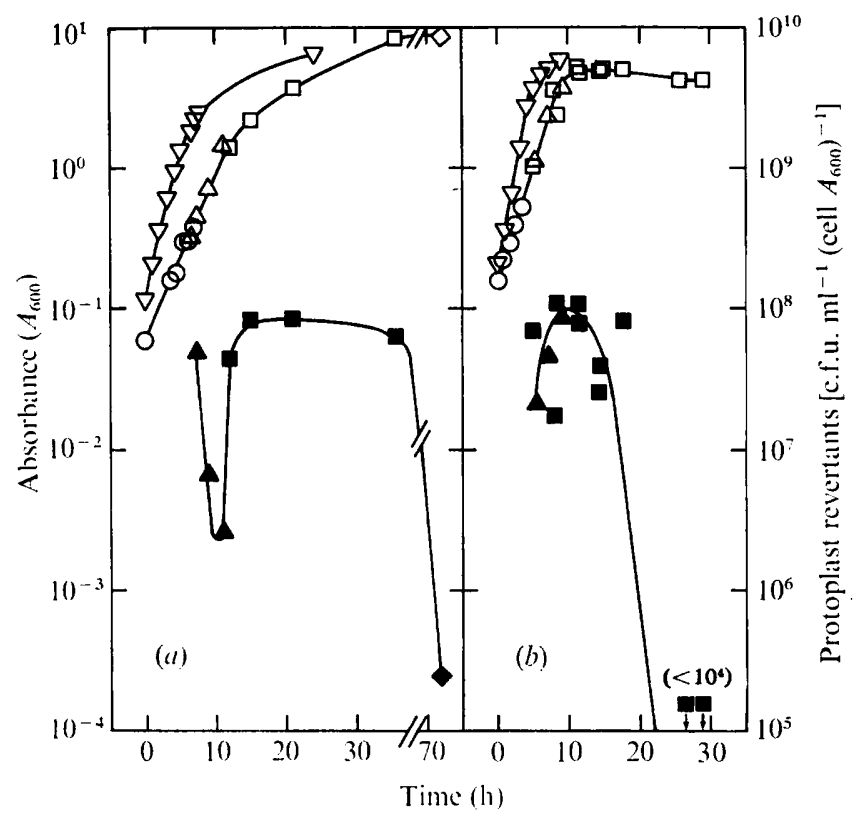

Fig. 1. Growth of $S$. fradiae and $S$. griseofuscus and regeneration of protoplasts as a function of growth phase. (a) Streptomyces fradiae M1 was grown in TS broth ( $\nabla$ ) or TS broth plus $0.4 \%$ glycine $(O, \triangle, \square, \diamond)$. The different symbols represent data from different experiments which have been superimposed to define the complete growth cycle. Mycelial fragments from one experiment $(\square)$ were refrigerated overnight before protoplast formation. Closed symbols represent the number of protoplast revertants per $A_{600}$ of cells taken from the corresponding growth phase (with glycine). (b) Streptomyces griseofuscus was grown in TS broth ( $\nabla$ ) or TS broth plus $0.8 \%$ glycine $(\bigcirc, \Delta, \square)$. Again, data from different experiments have been superimposed. Closed symbols represent the number of protoplast revertants per $A_{600}$ of cells taken from the corresponding growth phase (with glycine).

fragments of $S$. fradiae were plated, the maximum number of visible colonies was obtained in $2 \mathrm{~d}$. The asynchronous nature of protoplast regeneration was manifested quite dramatically by the variation in colony diameters at any given time. The large colonies from protoplasts that regenerate early, or from the small background of non-protoplasted cells, had a pronounced inhibitory effect on regeneration of nearby protoplasts. The inhibition was so severe that when $10^{3}$ to $10^{6}$ potentially viable (i.e. revertible) protoplasts were spread on one plate, only 500 to 1000 colonies developed, and these completely inhibited regeneration of the remaining protoplasts. Thus valid viable counts were obtained only if about 100 to 200 revertible protoplasts were spread per plate. This auto-inhibition was seen with protoplasts from cells which did not produce detectable levels of tylosin antibiotic(s) on plates, but was not seen when whole cells were plated, regardless of their ability to produce antibiotic(s). (Streptomyces fradiae $\mathrm{c} 373$ is not known to produce any antibiotic other than tylosins.)

In contrast, regeneration of protoplasts of $S$. griseofuscus was more rapid (half-time for colony development $<3 \mathrm{~d}$ ) and more synchronous, and no inhibition of regeneration was apparent when high concentrations of protoplasts were spread on plates (i.e. confluent lawns developed).

To determine the efficiency of regeneration per cell unit and to further characterize the events occurring during the phase in the growth cycle which yielded the pretoplasts that regenerated most efficiently, visual counts and absorbances of protoplasts and viable counts of cells before protoplast formation were also determined in one of the experiments $(\square, \square)$ described in Fig. 1(a). Since viable cell counts could not be determined directly because of 


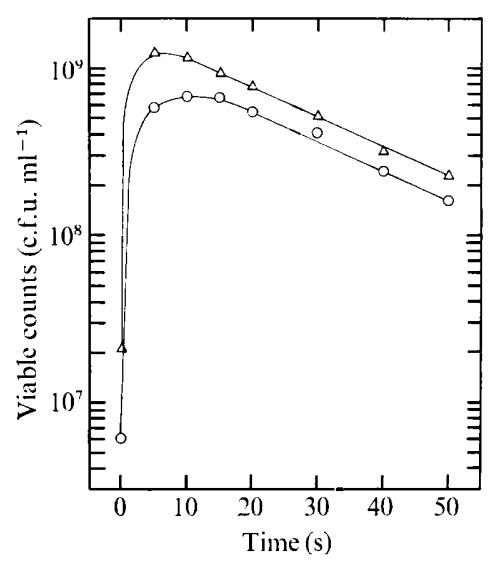

Fig. 2

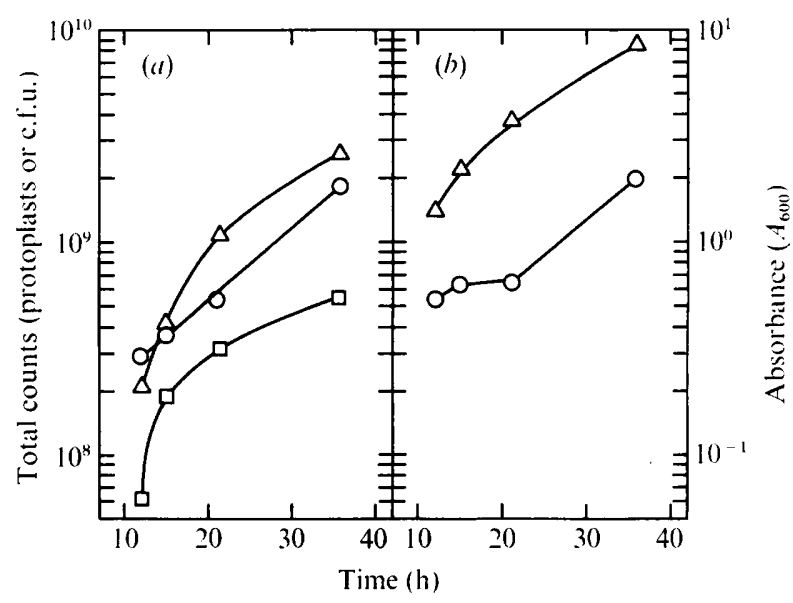

Fig. 3

Fig. 2. Fragmentation of $S$. griseofuscus and $S$. fradiae mycelia by ultrasound. TS broth $(10 \mathrm{ml})$ in a $50 \mathrm{ml}$ Erlenmeyer flask was inoculated with $0.05 \mathrm{ml}$ of ultrasonic fragments of $S$. griseofuscus at about $1 \times 10^{8} \mathrm{ml}^{-1}$ or $S$. fradiae at about $4 \times 10^{8} \mathrm{ml}^{-1}$. After $22 \mathrm{~h}$ incubation at $34{ }^{\circ} \mathrm{C}$, the resulting mycelia were treated with ultrasound at $76 \mathrm{~W}$ power output (see Methods). Samples were withdrawn after 5 or $10 \mathrm{~s}$ bursts, diluted and plated on $\mathrm{NC}$ agar for viable counts: $\bigcirc$, S. griseofuscus; $\triangle$, S. fradiae.

Fig. 3. Changes in growth parameters during the transition phase in S. fradiae. (a) $\bigcirc$, Total protoplasts; $\triangle$, c.f.u. after ultrasonic treatment; $\square$, protoplast revertants. (b) $\triangle$, Absorbance of cells; $\bigcirc$, absorbance of protoplasts. Data were obtained from the experiment described by $\square$ and $\square$ in Fig. 1(a), i.e. 12 to $36 \mathrm{~h}$.

the multicell nature of Streptomyces mycelia, a method to fragment mycelia ultrasonically was developed. Figure 2 shows the kinetics of fragmentation of early-stationary phase mycelia of $S$. fradiae and $S$. griseofuscus at $76 \mathrm{~W}$ ultrasonic power. Maximum colonyforming units (about $10^{8}$ per mycelia $A_{600}$ ) were obtained after 5 to $10 \mathrm{~s}$ with both strains. Extrapolation to zero dose suggests that about $50 \%$ of the maximum potential colonyforming units are recovered as viable counts after 5 to $10 \mathrm{~s}$ at $76 \mathrm{~W}$. Additional experiments (not shown) showed that this dose of ultrasound gives maximum colony-forming units from cells taken from different phases in the growth cycle.

Figure 3 shows for $S$. fradiae the changes with time in absorbances of cells before and after protoplasting, in viable counts of cells before and after protoplasting and in protoplast counts during the transition phase (12 to $36 \mathrm{~h}$ in Fig. $1 \mathrm{a}$ ). Several events occurred during this 'shift down' in growth rate beginning at a cell $A_{600}$ of about 1.5. An abrupt change in the rate of increase in total protoplasts occurred immediately $(12 \mathrm{~h})$; the time required to double the number of protoplasts increased from $2 \cdot 7$ to $11 \mathrm{~h}$. However, protoplast mass, as measured by $A_{600}$, stopped increasing at $12 \mathrm{~h}$, but began increasing proportionally with protoplast number at $22 \mathrm{~h}$. At about $17 \mathrm{~h}$, the cell $A_{600}$ accumulation shifted from the faster to the slower rate. Only after $22 \mathrm{~h}$, however, did the rate of viable cell count accumulation shift to the slower rate. An examination of the ratios of these parameters (data not shown) indicated that during the transition the average mass per protoplast decreased, the average mass per cell decreased, and the number of protoplasts per viable cell also decreased. The temporal sequence of these events suggests that cross-wall formation continued at a fairly rapid rate during the period when protoplast mass was not increasing appreciably. This is the time at which protoplasts regenerate cells most efficiently (Fig. 4). The maximum efficiency of protoplast regeneration per protoplast or per viable cell during this period was about $50 \%$. Since the number of viable counts was estimated to represent about one-half of the actual 


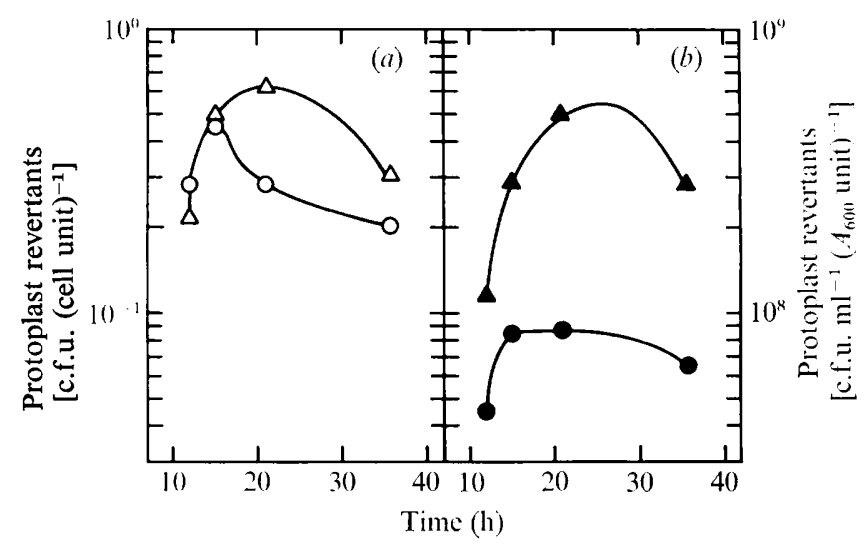

Fig. 4. Efficiency of $S$. fradiae protoplast reversion during the transition phase. (a) $\bigcirc$, Protoplast revertants per c.f.u. after sonication; $\triangle$, protoplast revertants per protoplast. $(b) \boldsymbol{\Delta}$, Protoplast revertants per protoplast $A_{600} ; \bigcirc$, protoplast revertants per cell $A_{600}$. Data are from the experiment described in Fig. 3.

Table 2. Genetic recombination in S. fradiae induced by protoplast fusion

\begin{tabular}{|c|c|c|c|c|}
\hline $\begin{array}{l}\text { Protoplasts } \\
\text { mixed }\end{array}$ & $\begin{array}{c}\text { PEG } \\
\text { treatment }\end{array}$ & $\begin{array}{l}\text { Dilution } \\
\text { medium }\end{array}$ & $\begin{array}{l}\text { Prototrophic } \\
\text { colonies after } \\
\text { regeneration }\left(\mathrm{ml}^{-1}\right)\end{array}$ & $\begin{array}{c}\text { Spectinomycin- } \\
\text { resistant } \\
\text { prototrophs }\end{array}$ \\
\hline $\begin{array}{l}\text { AR } 17+\text { AR } 30 \\
\text { AR } 17+\text { AR } 30 \\
\text { AR } 17+\text { AR } 30 \\
\text { AR } 17+\text { AR } 30\end{array}$ & $\begin{array}{l}+ \\
+* \\
- \\
-\end{array}$ & $\begin{array}{l}\mathrm{P}+\mathrm{PEG} \dagger \\
\mathrm{P}+\mathrm{PEG} \\
\mathbf{P} \\
\mathrm{H}_{2} \mathrm{O}\end{array}$ & $\begin{array}{l}2.4 \times 10^{4} \\
5 \cdot 0 \times 10^{2} \\
6 \cdot 6 \times 10^{3} \\
7 \cdot 0 \times 10^{1}\end{array}$ & $\begin{array}{c}6 / 7 \\
20 / 20 \\
8 / 8 \\
11 / 11\end{array}$ \\
\hline $\begin{array}{l}\text { AR } 17 \\
\text { AR } 17 \\
\text { AR } 17\end{array}$ & $\begin{array}{l}+ \\
- \\
-\end{array}$ & $\begin{array}{l}\mathrm{P}+\mathrm{PEG} \\
\mathrm{P} \\
\mathrm{H}_{2} \mathrm{O}\end{array}$ & $\begin{array}{l}2 \cdot 0 \times 10^{1} \\
2 \cdot 0 \times 10^{1} \\
2 \cdot 0 \times 10^{1}\end{array}$ & $\begin{array}{l}0 / 3 \\
0 / 6 \\
0 / 8\end{array}$ \\
\hline $\begin{array}{l}\text { AR30 } \\
\text { AR30 } \\
\text { AR30 }\end{array}$ & $\begin{array}{l}+ \\
- \\
-\end{array}$ & $\begin{array}{l}\mathrm{P}+\mathrm{PEG} \\
\mathrm{P} \\
\mathrm{H}_{2} \mathrm{O}\end{array}$ & $\begin{array}{l}<10^{1} \\
<10^{1} \\
<10^{1}\end{array}$ & $\begin{array}{l}0 / 0 \\
0 / 0 \\
0 / 0\end{array}$ \\
\hline
\end{tabular}

* The strains were treated with PEG separately, then mixed directly on the R2 plates.

$\uparrow$ This hypertonic medium contained $40 \%$ PEG in medium $\mathrm{P}$.

viable cells in the mycelium before ultrasonic treatment, the total protoplast counts appear to be somewhat lower than expected. This may be due to loss of protoplasts by lysis or clumping, or to inefficient visual counting of small protoplasts. In any event, the protoplast and viable counts were in close agreement, and a conservative estimate of protoplast reversion efficiency was between 25 and $50 \%$. Since protoplasts were washed three times by centrifugation and resuspension before plating, during which some clumping and loss in absorbance did indeed occur, the absolute efficiency of $S$. fradiae cell regeneration may actually be greater than $50 \%$. A similar analysis with $S$. griseofuscus indicated that nearly $100 \%$ of protoplasts from the transition phase will regenerate viable cells (data not shown).

\section{Genetic recombination induced by protoplast fusion}

In addition to having conditions for efficient formation and reversion of protoplasts, efficient genetic recombination is contingent upon having a means to fuse protoplasts and thus introduce genetic material from two different strains into a common cytoplasm. Polyethylene glycol was chosen for this work with Streptomyces since it has been shown to be effective in promoting protoplast fusion in a number of other systems. A genetic cross was carried out by fusion of protoplasts of auxotrophic $S$. fradiae strains AR30 (carrying met $A 5$, $\arg -2$ and $s p c-2$ ) and AR 17 (carrying $m e t B 2$ ). The $m e t A$ and $\arg$ genes were suspected to be 


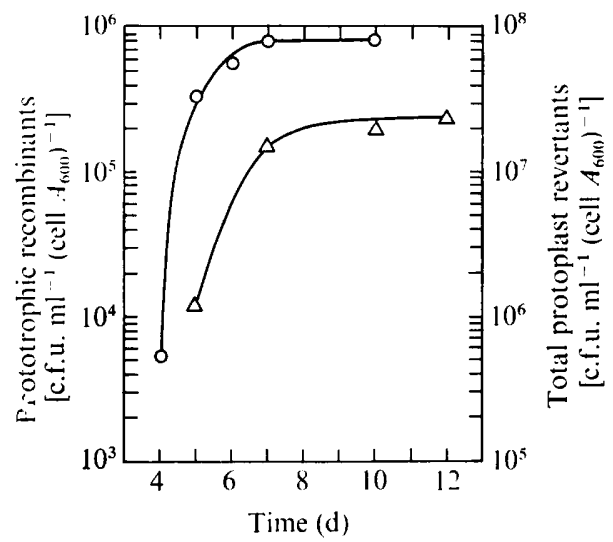

Fig. 5. Time course of recombinant formation after protoplast fusion. Streptomyces fradiae strains AR 11 and AR 30 were crossed by protoplast fusion (see Methods) and prototrophic recombinants were counted at various times after plating and normalized to the initial $\boldsymbol{A}_{600}$ of cells $(\Delta)$. Dilutions were made in medium $P$ without PEG. Also shown, for comparison, are the numbers of protoplast revertants from a culture at the optimum absorbance for regeneration $(\bigcirc)$.

linked since they were coinduced by treatment of $S$. fradiae with $N$-methyl- $N^{\prime}$-nitro- $N$ nitrosoguanidine (Seno, Radue \& Baltz, unpublished), a mutagen which produces high frequencies of multiple closely linked mutations (Drake \& Baltz, 1976). Since the $s p c$ and $m e t B$ genes are closely linked in $S$. coelicolor (mapping in the lower arc of the circular linkage map) but are not linked to met $A$ or $\arg (m e t A, \arg A, \arg B$ and $\arg C$ map in the upper arc of $S$. coelicolor), it was surmised that if the genetic map of $S$. fradiae is similar to that of $S$. coelicolor, many prototrophic recombinants should contain $s p c-2$ from AR 30 . This would rule out reversion of the metB2 marker of AR17 to prototrophy as an explanation for the results, since simultaneous reversion of $m e t B 2$ and forward mutation to spectinomycin resistance should occur at a frequency $<10^{-14}$, based upon spontaneous mutation frequencies of the two markers determined independently. A similar low frequency of simultaneous reversion of met $A 5$ and $\arg -2$ in AR 30 was also expected from reversion frequencies of the individual markers. Thus, any stable spectinomycin-resistant prototrophs arising from mixed protoplasts in this cross must be recombinants and not spontaneous mutants.

The results of this cross (Table 2) indicate that polyethylene glycol does induce $S$. fradiae to fuse and recombine at high frequencies. Putative recombinants were stable upon recloning and most contained the spectinomycin-resistance marker, ruling out reversion of $m e t B 2$ as an explanation of the results. A lower but significant frequency of recombinants was achieved without PEG treatment. These were presumably induced to fuse by the $\mathrm{Ca}^{2+}$ ions present in medium P (Fodor \& Alföldi, 1976). Dilution of mixed protoplasts in distilled water before plating reduced the number of recombinants 100 -fold. When the two protoplast preparations were treated with PEG separately before mixing on plates, only $2 \%$ as many recombinants developed as when the two were treated after mixing. Also when the two parents were plated separately under any condition, no spectinomycin-resistant prototrophic revertants were obtained.

In this experiment the fused protoplasts were diluted in medium $\mathrm{P}$ containing $40 \% \mathrm{PEG}$. In subsequent crosses between AR17 and AR30, dilutions were made in medium $P$ without PEG, and 5- to 10-fold higher recombinant frequencies were obtained (data not shown).

Figure 5 shows the time course of appearance of prototrophic recombinants in a cross between the AR30 and AR11 (containing cysDI) and, for comparison, the time course of appearance of regenerated prototrophic $S$. fradiae from a culture at optimum absorbance for regeneration $\left(A_{600} 2 \cdot 2\right)$. The frequency of recombinants in this cross was greater than $2 \times 10^{5}$ per cell $A_{600}$ or about $0.3 \%$ of the maximum potential revertible protoplasts, and 
$10^{5}$-fold above the cys $D^{+}$revertant frequency (not shown). The half-time for formation of visible recombinants was similar to the half-times obtained for regeneration of cells from protoplasts. In genetic crosses between whole cells carried out under standard conditions (Hopwood, 1967), no genetic recombinants (i.e. $<1$ in $10^{7}$ ) were detected (Radue \& Baltz, unpublished). Thus, the frequency of detection of genetic recombination with $S$. fradiae was enhanced at least $10^{4}$-fold by the technique of protoplast fusion.

Similar high frequencies of genetic recombinants were obtained by fusing singly marked auxotrophic mutants of $S$. griseofuscus (data not shown).

\section{DISCUSSION}

Development of an efficient method of genetic recombination by protoplast fusion is contingent on having the ability to form protoplasts from cells, to induce fusion of protoplasts and to regenerate cells from protoplasts. Genetic recombination will take place by virtue of the fact that two or more copies of homologous DNA reside in the same cytoplasm for a period of time. In fact the goal of any gene recombination system is to introduce homologous DNA from two sources into a common cytoplasm. Protoplast fusion makes this process very efficient by bypassing barriers encountered with other methods.

Okanishi et al. (1974) have demonstrated that $S$. griseus and $S$. venezuelae become highly sensitive to enzymic hydrolysis by lysozyme and lytic enzyme no. 2 after growth in a medium containing a partially growth-inhibitory concentration of glycine. I have found that this is also true for $S$. fradiae and $S$. griseofuscus, but that lysozyme treatment alone is sufficient. When care is taken to assure fairly homogeneous growth by inoculating growth media with fragments of mycelia prepared by ultrasonic treatment and by avoiding accumulation of large mycelial masses, then both species can be converted to protoplasts very efficiently with only 1 in $10^{6}$ to $10^{4}$ cells remaining osmotically resistant after lysozyme treatment.

Also when homogeneous cell growth is obtained and when mycelial masses do not exceed several hundred cells during the course of the experiment, cell growth can be readily monitored by absorbance or by viable counts after ultrasonic treatment of mycelia. The number of viable counts obtained at the optimum ultrasonic dose appears, by extrapolation, to be about one-half of the actual number of viable cells in the mycelia at zero dose, consistent with random intracell breakage, and is in close agreement with the number of protoplasts liberated by lysozyme treatment.

Examination of the efficiency of cell regeneration from protoplasts throughout the growth cycle indicates that a physiological state for optimum cell regeneration is reached during the transition between the exponential and stationary growth phases. The efficiencies of cell regeneration per protoplast or per viable cell with transition-phase protoplasts of $S$. fradiae and S. griseofuscus are about 50 and $100 \%$, respectively. An examination of relative increases in $S$. fradiae protoplast counts and mass and cell viable counts and mass during the transition phase suggests that peak efficiency is reached during a period when cell wall synthesis occurs without significant accumulation of protoplast mass. After $S$. fradiae or $S$. griseofuscus cells enter the stationary phase of growth, the efficiency of protoplast regeneration decreases dramatically. Streptomyces fradiae protoplasts from early-exponential phase $\left(A_{600}\right.$ about 0.4$)$ also regenerate efficiently, while those from mid- to late-exponential phase ( $A_{600}$ about 0.5 to 1.0$)$ regenerate poorly.

Okanishi et al. (1974) reported that protoplasts of $S$. griseus and $S$. venezuelae prepared from mycelia in the mid-exponential growth phase regenerated cells quite efficiently on medium R2, but did not indicate the method used to determine the growth phase.

The process of cell regeneration from $S$. fradiae protoplasts is generally slow and asynchronous, and protoplasts from different phases of the growth cycle regenerate with characteristic half-times. During regeneration, the first colonies appearing have a marked inhibitory effect on regeneration of nearby protoplasts. The phenomenon is apparently not 
due to antibiotic synthesis since no differences are seen between tylosin producers and nonproducers. A similar observation in Bacillus subtilis has been attributed to excretion of autolytic enzyme(s) which impedes cell wall synthesis during cell regeneration (DeCastroCosta \& Landman, 1977).

Protoplasts of $S$. fradiae can be induced to fuse by treatment with polyethylene glycol, and fused strains containing different auxotrophic markers readily recombine and regenerate stable prototrophic recombinants on medium R2. Frequencies of recombinants as high as $0.3 \%$ of the parental protoplasts have been achieved. Since this frequency of recombinants was not corrected for the loss in revertible protoplasts due to PEG treatment (which has been up to fivefold in some experiments) or to possible loss in viability before prototrophic recombinants are formed on plates, the actual frequency of prototrophic recombinants per viable fused protoplast may be significantly higher. The method has also been used to obtain high frequencies of genetic recombinants with $S$. griseofuscus.

During the preparation of this manuscript, a similar technique of protoplast fusion for Streptomyces was reported by Hopwood et al. (1977). Their method, however, was modelled on a technique used for fusion of mammalian cells (Pontecorvo et al., 1977) which employs a lower molecular weight PEG (mol. wt 1540) for fusion, while the method described here is similar to the Bacillus system (Fodor \& Alföldi, 1976; Schaeffer et al., 1976) which employs PEG 6000. With the method of Hopwood et al. (1977), fused protoplasts were plated undiluted, and recombinant frequencies were determined after spore formation on confluent lawns of mycelial growth. This method works well with $S$. coelicolor, $S$. parvulus, $S$. lividans and $S$. griseus but does not work well with species such as $S$. acrimycini (Hopwood et al., 1977) or $S$. fradiae (described here) which produce auto-inhibitory activities. The method described here gives 10 - to 100 -fold fewer cells surviving lysozyme treatment and higher frequencies of cell regeneration than reported by Hopwood et al. (1977).

In spite of the technical differences, both systems give very high frequencies of genetic recombinants, and protoplast fusion should be an important new general technique to aid in genetic analysis and strain development in Streptomyces. In addition, the technique has recently been used to enhance the frequencies of interspecies genetic recombinants in Streptomyces (Godfrey, Ford \& Huber, personal communication) and should be a powerful tool to increase variability and exchange of gene pools within Streptomyces. Isolation of recombinants may enhance the probability of finding new and potentially useful metabolites such as antibiotics. Adaptation of the methodology of protoplast fusion to other bacterial species may be a way to extend genetic analysis to species which currently lack efficient mating systems.

The author would like to thank B. Byers for technical assistance, O. Godfrey for communication of results prior to publication, and L. Day, C. Hershberger and D. McGilvray for critically reading the manuscript.

\section{REFERENCES}

Akagawa, H., OKanishi, M. \& Umezawa, $H$. (1975). A plasmid involved in chloramphenicol production in Streptomyces venezuelae: evidence from genetic mapping. Journal of General Microbiology 90, 336-346.

Alačević, M. (1976). Recent advances in Streptomyces rimosus genetics. In Second International Symposium on the Genetics of Industrial Microorganisms, pp. 513-519. Edited by K. D. Macdonald. New York: Academic Press.

Alačević, M., Strašek-Vešligaj, M. \& Sermonti, G. (1973). The circular linkage map of Strepto- myces rimosus. Journal of General Microbiology 77, 173-185.

AnNé, J. \& Peberdy, J. F. (1976). Induced fusion of fungal protoplasts following treatment with polyethylene glycol. Journal of General Microbiology 92, 413-417.

Bibb, M. J., Freeman, R. F. \& Hopwood, D. A. (1977). Physical and genetical characterization of a second sex factor, SCP2, for Streptomyces coelicolor A3(2). Molecular and General Genetics 154, $155-166$. 
CoATs, J. H. (1976). Genetic recombination in Streptomyces achromogenes var. rubradiris. In Second International Symposium on the Genetics of Industrial Microorganisms, pp. 521-530. Edited by K. D. Macdonald. New York: Academic Press.

CoATs, J. H. \& Roeser, J. (1971). Genetic recombination in Streptomyces bikiniensis var. zorbonensis. Journal of Bacteriology 105, 880-885.

DeCastro-Costa, M. R. \& Landman, O. E. (1977). Inhibitory protein controls the reversion of protoplasts and L forms of Bacillus subtilis to the walled state. Journal of Bacteriology 129, 678-689.

Delić, V., Hopwood, D. A. \& Friend, E. J. (1970). Mutagenesis by $N$-methyl- $N^{\prime}$-nitro- $N$-nitrosoguanidine (NTG) in Streptomyces coelicolor. Mutation Research 9, 167-182.

Drake, J. W. \& BALTZ, R. H. (1976). The biochemistry of mutagenesis. Annual Review of Biochemistry 45, 11-37.

Ferenczy, L., Kevei, F. \& Szegedi, M. (1975). High-frequency fusion of fungal protoplasts. Experientia 31, 1028-1030.

FoDOR, K. \& AlFöldI, L. (1976). Fusion of protoplasts of Bacillus megaterium. Proceedings of the National Academy of Sciences of the United States of America 73, 2147-2150.

Friend, E. J. \& Hopwood, D. A. (1971). The linkage map of Streptomyces rimosus. Journal of General Microbiology 68, 187-197.

Hopwood, D. A. (1967). Genetic analysis and genome structure in Streptomyces coelicolor. Bacteriological Reviews 31, 373-403.

Hopwood, D. A. (1976). Genetics of antibiotic production in Streptomyces. In Microbiology 1976, pp. 558-562. Edited by D. Schlessinger. Washington: American Society for Microbiology.

Hopwood, D. A., Chater, K. F., Dowding, J. E. \& Vivian, A. (1973). Advances in Streptomyces coelicolor genetics. Bacteriological Review's 37 , $371-405$.

Hopwood, D. A., Wright, H. M., Bibb, M. J. \& CoHEN, S. N. (1977). Genetic recombination through protoplast fusion in Streptomyces. Nature, London 268, 171-174.

Jones, C. W., Mastrangelo, I. A., Smith, H. H. \& LiU, H. Z. (1976). Interkingdom fusion between human (HeLa) cells and tobacco hybrid (GGLL) protoplasts. Science 193, 401-403.

OKanishi, M., Suzuki, K. \& Umezawa, H. (1974). Formation and reversion of streptomycete protoplasts: cultural conditions and morphological study. Journal of General Microbiology 80, 389-400.

Pontecorvo, G., Riddle, P. N. \& Hales, A. (1977). Time and mode of fusion of human fibroblasts treated with polyethylene glycol (PEG). Nature, London 265, 257-258.

Power, J. B., Frearson, E. M., Hayward, C., George, D., Evans, P. K., Berry, S. F. \& Cocking, E. C. (1976). Somatic hybridization of Petunia hybrida and $P$. parodii. Nature, London 263, 500-502.

Schaeffer, P., Cami, B. \& Hotchisiss, R. D. (1976). Fusion of bacterial protoplasts. Proceedings of the National Academy of Sciences of the United States of America 73, 2151-2155.

SiPICZKI, M. \& Ferenczy, L. (1977). Protoplast fusion of Schizosaccharomyces pombe auxotrophic mutants. Molecular and General Genetics 151, 77-81.

Wright, L. F. \& Hopwood, D. A. (1976a). Identification of the antibiotic determined by the SCP1 plasmid of Streptomyces coelicolor A3(2). Journal of General Microbiology 95, 96-106.

WRIGHT, L. F. \& Hopwood, D. A. (1976b). Actinorhodin is a chromosomally-determined antibiotic in Streptomyces coelicolor A3(2). Journal of General Microbiology 96, 289-297. 